\title{
Amphibious and sprawling locomotion: from biology to robotics and back
}

\author{
Auke J. ljspeert \\ EPFL - Ecole Polytechnique Fédérale de Lausanne, Switzerland. Auke.ljspeert@epfl.ch
}

ORCID: 0000-0003-1417-9980

Keywords: amphibious and sprawling locomotion, walking, swimming, biorobotics, neuroscience, paleontology

\section{Abstract}

A milestone in vertebrate evolution, the transition from water to land, owns its success to the development of a sprawling body plan that enabled an amphibious lifestyle. The body, originally adapted for swimming, evolved to benefit from limbs that enhanced its locomotion capabilities on submerged and dry grounds. The first terrestrial animals used sprawling locomotion, which is a type of legged locomotion in which limbs extend laterally from the body (as opposed to erect locomotion in which limbs extend vertically below the body). This type of locomotion, exhibited for instance by salamanders, lizards, and crocodiles, has been studied in different fields such as neuroscience, biomechanics, evolution, and paleontology. Robotics can benefit from these studies to design amphibious robots capable of swimming and walking, with interesting applications in field robotics, in particular for search and rescue, inspection, and environmental monitoring. In return, robotics can also provide useful scientific tools to test hypotheses in neuroscience, biomechanics, and paleontology. For instance, robots have been used to test hypotheses about the organization of neural circuits that can switch between swimming and walking under the control of simple modulation signals, as well as to assess which were the most likely gaits of extinct sprawling animals. I will here review different aspects of amphibious and sprawling locomotion, namely in terms of gait characteristics, neurobiology, numerical models, and sprawling robots, and discuss fruitful interactions between robotics and other scientific fields.

\section{INTRODUCTION}

Locomotion in animals and robots is a fascinating phenomenon that results from complex interactions between the environment, body, sensors, actuators (muscles or motors), and multiple control loops. Understanding locomotion principles is important for many fields: robotics, sports science, medicine, rehabilitation, neuroscience, biomechanics, evolution, and paleontology. Many fruitful interactions can take place between these different fields. In particular, robotics can benefit from biology to develop robots that approach animal locomotor skills [1], [2]. In return, it can also provide interesting tools for scientific research [3]-[6]. Indeed, 
robotics - the science of integration of many components - is ideally suited to offer tools to design, analyze, and understand the complex, high dimensional and non-linear interactions between all the components involved in locomotion.

While robotics has a long tradition in the design and control of legged robots [7]-[11], there has been less work on amphibious and sprawling locomotion which will be the focus of this review. This article will investigate amphibious and sprawling locomotion as exhibited by salamanders, lizards, and crocodiles, i.e. amphibians and reptiles with four laterally extending legs and elongated bodies ${ }^{1}$ (Figures 1, 2, and 3). This type of locomotion combines several interesting characteristics. It involves not only four limbs but also trunk and tail movements, typically with important lateral movements of the whole body [12]. For ground locomotion, sprawling locomotion involves large support polygons and low centers of gravity (as opposed to cursorial mammalian quadruped locomotion with erect postures that have small support polygons and high centers of gravity). Salamanders, lizards, and crocodiles have adapted to many different types of environments from water to trees, and from swamps to deserts. Each of these animals is capable of multimodal locomotion, i.e. to switch between different modes of locomotion depending on the environment. These modes of locomotion range from anguilliform swimming, paddling, aquatic stepping, crawling, walking, galloping (in crocodiles), to even more exotic modes of locomotion such as sand swimming by the sand fish lizard [13], and maneuvers in the air by the gecko [14]. As we will see in this review, these characteristics present interesting opportunities and challenges for robotics. Also because of its key place in evolution, amphibious and sprawling locomotion is important to study in paleontology, evolution, biomechanics, and neurobiology. Indeed, all reptiles, birds, and mammals (including humans) have evolved from ancestors with body plans that share many similarities with modern sprawling animals [15]-[22],

In this review article, I will first present characteristics of sprawling locomotion in salamanders, lizards, and crocodiles (Section 2). I will then review what is known about the underlying locomotor neural circuits (Section 3) and their computational models (Section 4). Next, I will present a series of robots capable of amphibious and sprawling locomotion (Section 5) and their control frameworks (Section 6). I will also present the results of a project in robotic paleontology (Section 6). Finally, I will conclude with a discussion and an outlook (Section 7).

\footnotetext{
${ }^{1}$ Note that crocodiles and some lizards can also switch to an erect or semi-erect posture. Also many insects exhibit a sprawling posture but will not be reviewed here.
} 

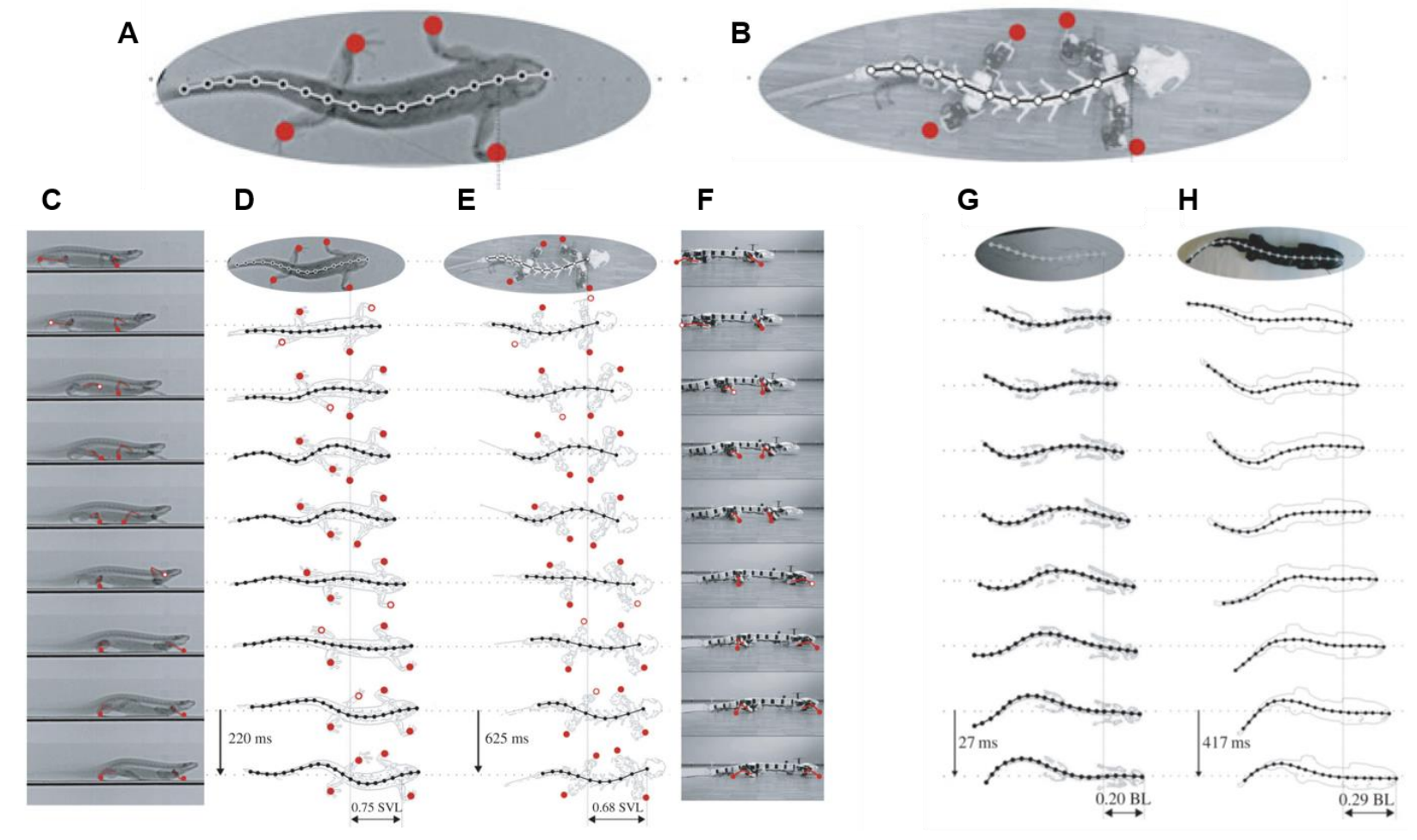

Figure 1 : Amphibious and sprawling gaits of the salamander Pleurodeles waltl and of the robot Pleurobot (from [23], with reprint permission). A: snapshot from a cineradiography. Filled red dots indicate limbs on the ground. B: Snapshot of Pleurobot replaying the same postures from the salamander. C: corresponding side view of the salamander. D: consecutive snapshots during one cycle of lateral sequence walk. Filled red circles indicate limbs in stance, empty red circles indicate limbs in swing. Snapshots are separated by $220 \mathrm{~ms}$. SVL stands for Snout-Vent Length, a typical length measure in sprawling animals with tails. BL stands for body length. E: consecutive snapshots of Pleurobot replaying the same postures as panel D. Snapshots are separated by $625 \mathrm{~ms}$. F: corresponding side view of Pleurobot. G: consecutive snapshots during one cycle of anguilliform swimming of the salamander. Snapshots are separated by $27 \mathrm{~ms}$. H: consecutive snapshots of Pleurobot replaying the same postures as panel G. Snapshots are separated by $417 \mathrm{~ms}$. Notice the similarities of lateral and forward displacement between Pleurobot and the salamander.

\section{CHARACTERISTICS OF AMPHIBIOUS AND SPRAWLING LOCOMOTION}

From a robotics point of view, animals like salamanders, lizards, and crocodiles are hyper redundant structures, i.e. they have many more actuated degrees of freedom (actuated joints) than would be in principle needed for changing the position and orientation of a body in 3D space. Indeed, one could view those animals as snakes with four legs. It is therefore not surprising that those animals can perform a large variety of possible locomotor modes.

Many studies have been performed to investigate these modes of locomotion in different species. Typically, most of those studies have looked at the animal kinematics (e.g. body deformations and displacements over time) using (high-speed) video recordings [18], [24]-[26] or cineradiography, i.e. X-ray videos [27], [28], [23]. Some of these studies have also investigated 
fluid dynamics [29], [30], ground reaction forces [16], [31], [28], and/or muscle activity through electromyography [32]-[36]. Characterization of the mechanics of sprawling locomotion can be found in [16], [27], [31]. A few studies have investigated metabolic cost [37], [38]. For a review of salamander locomotion see Karakasiliotis et al [39]. For a comparative study of salamander, skink, iguana and caiman, see Nyakatura et al [28]. For reviews of Gecko locomotion see [12], [40].

For fast locomotion in water, salamanders and newts (i.e. aquatic salamanders) typically use an anguilliform swimming mode (for slower locomotion they can use paddling or aquatic stepping [41]). Such a mode of locomotion is characterized by lateral undulations of the body traveling from head to tail with a wavelength corresponding approximately to a body length, with limbs folded backwards against the body [33], [42], [34], [26], [39], [23]. Similar swimming gaits have been observed in lizards [43], [44] and in crocodiles [30].

For ground locomotion, salamanders perform walking gaits that combine lateral movements of the body with leg movements. The lateral undulations are typically S-shaped standing waves with nodes at the girdles, i.e. the attachments points of the limbs to the body [23], [39]. For faster gaits, the lateral undulations sometimes switch from standing waves to traveling waves [18], and this is also observed in lizards [25]. The body-limb coordination is important, and animals keep a phase relationship between body and limbs such that limbs in swing project maximally forward when the body is maximally bent towards the other side (Figure 1D and 1E). Robotic studies have allowed the exploration of other phase relationships and shown that the particular one observed in animals is optimal in terms of forward speed [45], [46].

Several methods can be used to quantitatively characterize ground walking locomotion. These come from animal studies and are also useful in robotics. One method is Hildebrand's classification of footfall patterns [47]. That classification is based on measuring (i) the duty factor, i.e. the ratio between stance duration and stepping duration, and (ii) the time between hindlimb and forelimb contacts on the same side. According to that classification, salamanders mainly use two types of gaits: lateral sequence walk (for slow locomotion) and walking trot (for faster locomotion). In a lateral sequence, there is a sequence of footfalls from a hindfoot that is followed by the touchdown of the ipsilateral (i.e. same side) forefoot, then the contralateral hindfoot and finally the contralateral forefoot. In a trot, diagonally opposed limbs are in-phase (they touch the ground at the same time), and left/right and hind/fore limbs in antiphase. In both cases, the duty factors are larger than 0.5 (in the order of 0.6 to 0.8 ), which corresponds to walking gaits in Hildebrand's classification (as opposed to running gaits that have duty factors smaller than 0.5 and hence flight phases). For very fast locomotion, lizards have been observed to use running trotting gaits, and even bipedal gaits [48], [49]. And crocodiles are capable of very fast bounding and galloping gaits [50], [51].

In addition to footfall patterns, it is important to measure other characteristics for quantifying sprawling terrestrial gaits. With Nyakatura and colleagues [28], we have proposed to look at four quantities namely body height, lateral bending of the vertebral column, and long-axis rotation (LAR) and retraction in the proximal limb joints (shoulder and hip), see Figure 4 A-C. These four quantities define a 'sprawling gait space' (SGS) that is very useful to compare different possible 
gaits of sprawling animals. In particular, the SGS allowed for a careful evaluation of these quantities for the salamander, skink, iguana, and caiman using cineradiography (Figure 4D). The SGS could be useful for both biologists and roboticists. It is waiting to be populated with gaits from other sprawling animals and robots (or gaits of different ontogenetic stages of an animal or gaits at different speeds of the same animal/robot).

Note that other interesting locomotor behaviors of sprawling animals have been studied, such as sand-swimming of the desert-dwelling sandfish lizard [13], the surprising roles of the Gecko's tail during rapid climbing, aerial descent, and gliding [14], the bipedal running on water of the basilisk lizard [52] and the quadrupedal trotting on water of the gecko [53].

\section{THE NEUROBIOLOGY OF AMPHIBIOUS AND SPRAWLING LOCOMOTION}

The sprawling animal whose locomotor circuit has been most studied is likely the salamander, in particular the Pleurodeles waltl (very few studies have been made of reptile locomotor circuits, except for the turtle [54], [55]). Like in other vertebrate animals, the spinal cord is essential for locomotion control. It is not simply relaying motor commands but contains a distributed system of complex and sophisticated neural control circuits made of networks of coupled neural oscillators (the central pattern generators) and of reflexes [56]. These neural circuits constitute complete controllers that combine feedforward and feedback control [57]. They can generate many motor behaviors with only minimal input from descending pathways [58], [59]. Conceptually, the spinal cord is organized like a puppet on strings [60], in which complex movements can be produced by modulating the amplitude and timing of a limited number of descending pathways (i.e. pulling a few strings).

In the salamander, there are two types of central pattern generators (CPGs), an axial CPG that activates axial muscles in the trunk and the tail [61], and limb CPGs that activate limb musculature [62], [63]. Both types of CPGs are composed of multiple coupled neural oscillators, i.e. neural pools that can oscillate independently and that are coupled through connections between interneurons for producing synchronized motor behavior. For instance, one can surgically isolate segments and even hemi-segments (i.e. left or right half segments) of the axial CPG and induce rhythmic activity with pharmacological stimulation [61]. The axial CPG is hence a double chain of oscillators with reciprocal inhibition to produce left-right alternation as in the lamprey [56]. Similarly, the limb CPG appears to be composed of separate neural oscillators that specifically control flexor and extensor muscles and that are coupled with inhibitory and excitatory couplings [62], [63].

Researchers have therefore hypothesized that the salamander axial CPG has been inherited from the earliest vertebrates which are assumed to have had a similar arrangement as modern lampreys, and that the circuit has been extended with fin and then limb CPGs during evolution [18], [19], [34], [64], [65]. This hypothesis is supported by the similarities between lamprey and salamander locomotor circuits [66] and their nearly identical anguilliform swimming modes. 
Related to the puppet analogy mentioned above, an impressive feature of the salamander locomotor circuits is that locomotion can be initiated and modulated by simple stimulation of descending pathways from higher brain regions. Indeed the electrical stimulation of the mesencephalic locomotor region (MLR, a part of the brain stem that projects to the spinal cord and that is known to control movement initiation [67]) in a decerebrated salamander will initiate locomotor behaviors and even induce gait transitions depending on the level of stimulation [68]. The frequency of movements is proportional to the level of stimulation. At low stimulation, slow limb movements are activated, and the frequency of these movements then increases with the level of stimulation. Interestingly, when passing a threshold at higher intensities, the limbs are folded against the body and rapid swimming movements are activated, i.e. a gait transition is induced. From a dynamical systems perspective, this represents a bifurcation between two very different regimes under the control of a simple drive signal. Similar gait transitions induced by electrical stimulation of the midbrain have been observed in other vertebrates, e.g. transitions between stepping and flapping wings in birds [69], and transitions between walking, trotting, and galloping in cats [58].

For more information about salamander neurophysiology see [70]-[73]. Many points remain to be investigated, in particular related to how multimodal sensory feedback interacts with the CPG circuits, and how different motor behaviors can be activated and modulated by various descending pathways. As we will see next, computational models can play an important role in deciphering the organization and mechanisms of locomotor circuits (Section 4) and also serve as controllers for robots (Section 6).

\section{COMPUTATIONAL NEUROSCIENCE MODELS}

Computational models of salamander locomotor circuits have helped investigating the underlying neural mechanisms described in Section 3. These models range from abstract models made of coupled oscillators [74], [65], [75], leaky integrator neurons [64], integrate-and-fire neurons [75], [76], to detailed Hodgkin-Huxley-like neurons [77]. See [72] for a review.

An important focus has been to investigate the neural mechanisms of gait transition between swimming and walking [64], [78], [65]. Using a neural network model made of leaky-integrator neurons coupled to a 2D biomechanical simulation of the musculoskeletal system, I could demonstrate that an axial CPG based on a lamprey-like swimming circuit could be extended by limb CPGs to allow transitions between anguilliform swimming and walking [64]. In that model, the transition was obtained by differential activation of distinct descending pathways to axial and limb oscillators. When solely the axial CPG was activated, this led to anguilliform swimming. When limb oscillators were also activated, this led to the salamander walking trot gait. The activation of the limb CPGs forced the axial CPG to produce a standing wave due to strong couplings from limb to axial oscillators. The model could also produce turning behavior during swimming and walking by differential stimulation of the left and right descending pathways to the axial CPGs. 


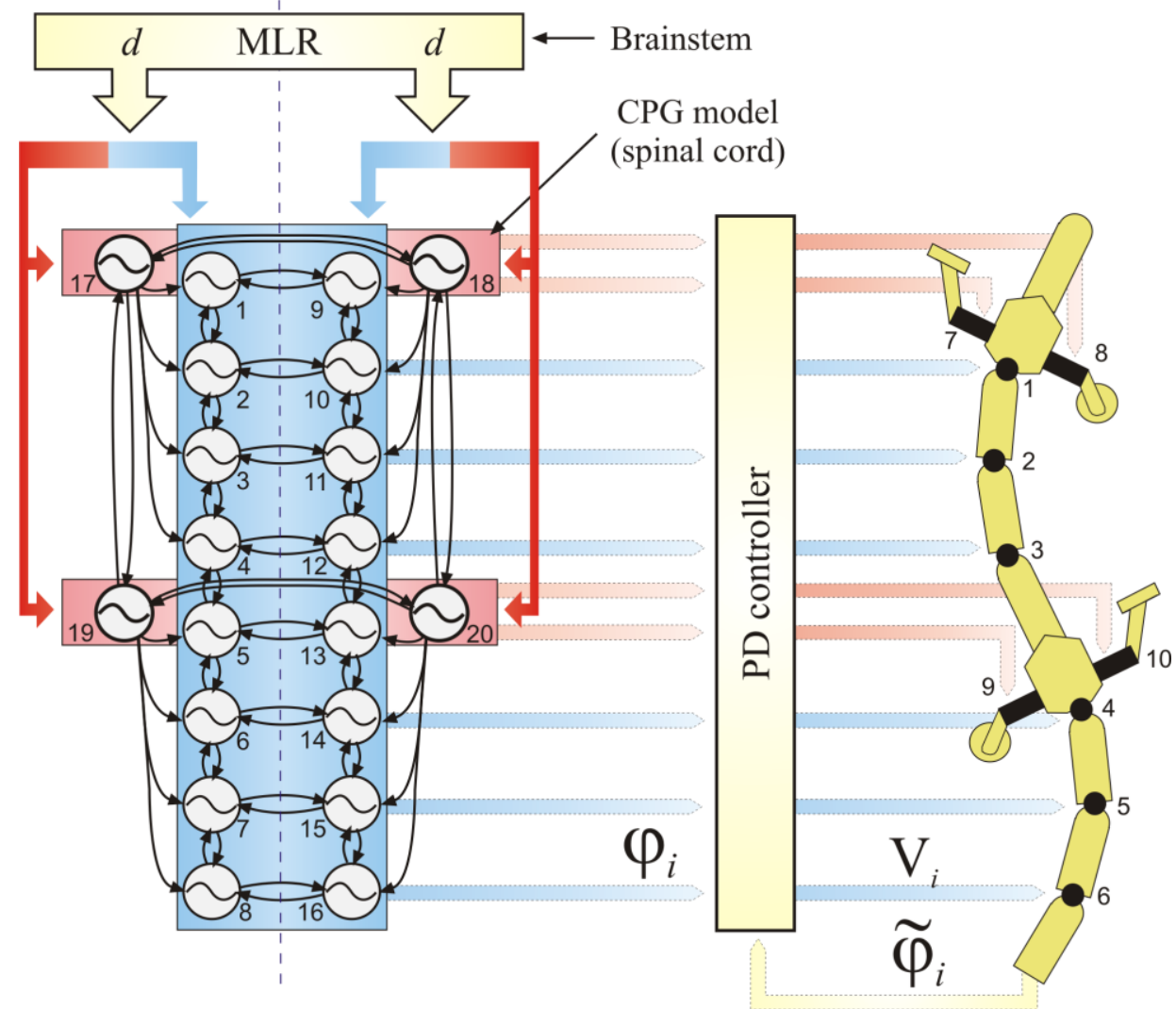

Figure 2: Schematic view of the simulation of the salamander spinal locomotor circuits and the control of a salamander like robot as presented in [65] (reprinted with permission). CPG stands for central pattern generator. MLR stands for mesencephalic locomotor region. The model is activated by a drive signal $d$ representing activity from the descending pathways from MLR. The axial CPG (in blue) and limb CPG (in red) are modeled as systems of coupled oscillators. The outputs of the oscillators determine the desired angles $\varphi_{i}$ provided to proportional-derivative (PD) feedback controllers that control the motor torques through their voltage $V_{i}$ given the measured angles $\widetilde{\varphi_{\iota}}$. Modulation of the drive signal induces a walking gait at low drive, and a swimming gait a high drive like in the real salamander.

In a follow-up model made of coupled oscillators and tested in a real salamander-like robot, Salamandra robotica [65] (Figure 2, see also Section 5), we extended the model with a saturation mechanism of the limb CPGs. The goal was to investigate the mechanisms underlying the MLR stimulation experiment and the automatic transition between walking and swimming (see Section 3), as well as the fact that frequencies of walking and swimming do not overlap but show distinct ranges in salamander. Compared to the previous neural models, two hypotheses were postulated: (i) that limb CPGs have a saturation mechanism that prevents them to reach high frequencies when stimulated above a drive threshold, and (ii) that limb oscillators have lower intrinsic frequencies than axial oscillator when receiving the same level of stimulation. By designing a neural circuit model that implements these two hypotheses, we were able to generate automatic transitions between walking and swimming by varying a single global drive signal applied to both axial and limb CPGs like the MLR stimulation experiment. The transitions exhibit several features of real salamander transitions such as very rapid switches between the 
two gaits (within less than two cycles), switches between traveling waves of lateral undulations for swimming and standing waves for walking, and jumps of frequencies between slow walking frequencies and fast swimming frequencies. Interestingly, additional experiments on isolated axial and limb CPGs of the salamander confirmed the second hypothesis, namely that limb CPGs intrinsically oscillate at lower frequencies than axial oscillators (Supplementary material of [65]). Such differences had not been noticed before because couplings between axial and limb CPGs tend to impose synchronization, i.e. to generate a common resulting frequency, that had hidden the possibility that these CPGs have different intrinsic frequencies.

The role of sensory feedback has received less attention so far. It is known from lamprey modeling work that axial stretch feedback can help a neuromechanical simulation of a swimming lamprey to resist to perturbations such as entering a speed barrier compared to open-loop swimming without feedback [79]. In preliminary results [74], [80], we showed that similar feedback could possibly explain the transformation of a traveling wave of body undulation in water to a standing wave on ground [74], because of the difference of interaction forces between water and ground (in water, hydrodynamic forces are strongly directional, with higher forces perpendicular to the body and lower forces parallel to the body, compared to friction forces on ground, which are more uniform). In [76], we investigated the potential role of stretch feedback within the limbs in terrestrial gaits and transitions between slow lateral sequence walks and faster walking trots in a neuromechanical simulation with an integrate-and-fire neural network. It was found that while walking trot gaits could easily be generated without sensory feedback, sensory feedback was necessary to generate lateral sequence walks (at least for a fixed CPG circuit). With the addition of sensory feedback, transitions between slow lateral sequence walks and faster walking trots were obtained by simply increasing the drive to the limb CPGs.

Simple turning behaviors can be obtained with differentially activating axial CPG oscillators. Typically by providing more drive to one side, leads to turning towards that side [45], [64], [65]. During ground locomotion with more realistic 3D limbs, Harischandra and colleagues found that more complex modulation of limb movements is necessary, in particular with side stepping movements of limbs [81]. A similar observation was made by Liu and colleagues in another neuromechanical model [82]. 

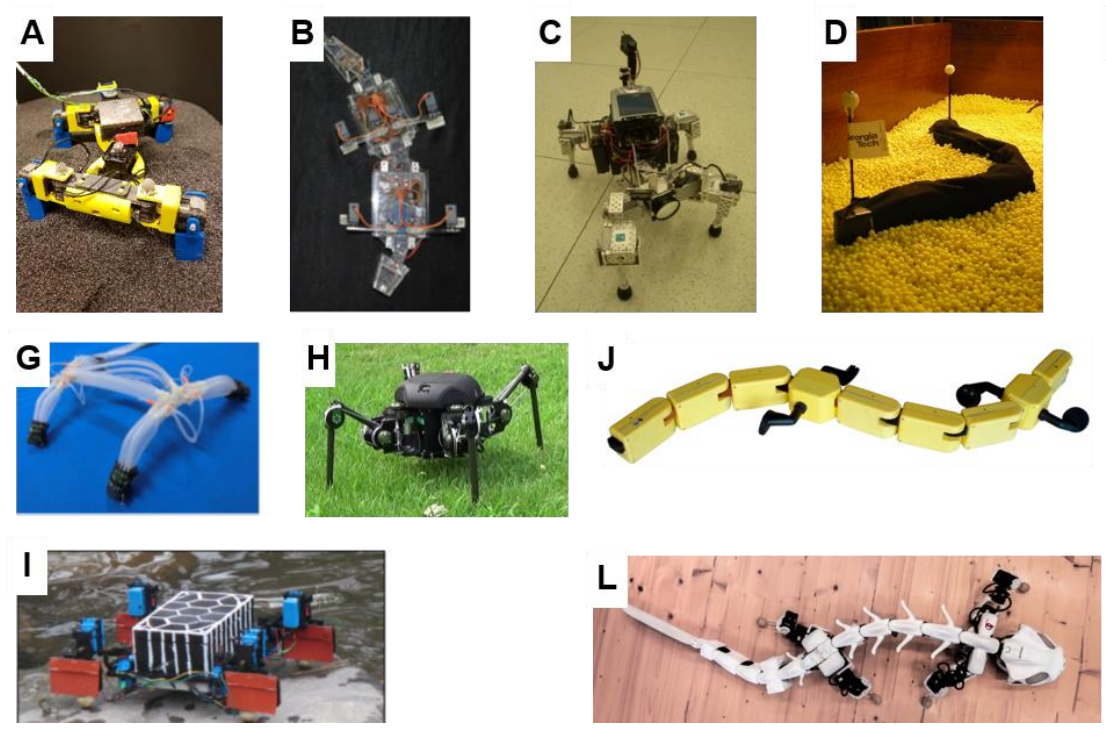
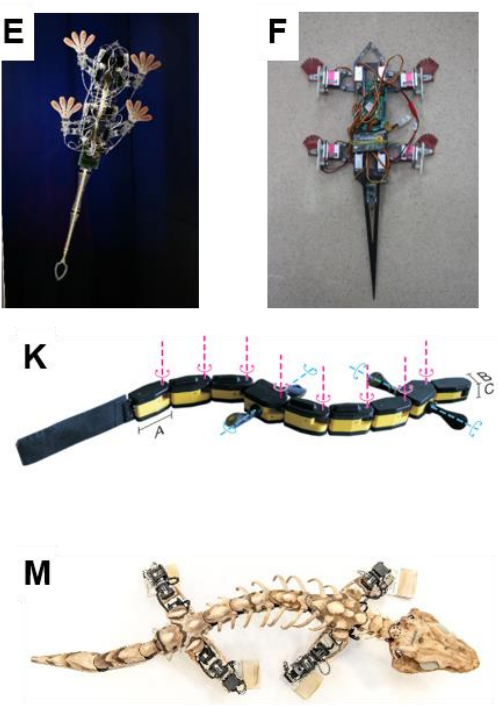

Figure 3: Robots with sprawling postures. A: Salamander-like robot [46]. B: Alligator-like robot [83]. C: AMOS-WD02 [84].D: Sand swimming robot [85]. E: StickyBot [86]. F: RoboClaw [87]. G: Soft amphibious robot [88]. H: TITAN XIII [89]. I: RoboTerp [90]. J: Salamandra robotica I [65]. : K: Salamandra robotica II [45]. L: Pleurobot [23]. M: OrOBOT [28]. All pictures with reprint permissions from authors or publishers.

\section{ROBOTS CAPABLE OF AMPHIBIOUS AND SPRAWLING LOCOMOTION}

Compared to the large number of legged robots, there are not that many salamander or lizardlike sprawling robots, i.e. robots that have a sprawling posture and an articulated spine capable of lateral movements. See Figure 3 and Table 1 for some examples.

One of the first roboticists to investigate sprawling robots with lateral spine undulations was Tony Lewis in his PhD thesis in 1996 [91]. He developed the quadruped robot Geo that could be reconfigured to have a sprawling posture with lateral spine movements [91]. Since then several similar robots were designed mainly for ground locomotion, for instance Robo-Salamander [92], an alligator inspired robot [83], and salamander-inspired robots [84], [46]. Only few sprawling robots with articulated spines are capable of amphibious locomotion [23], [45], [65], [88]. Most sprawling robots tend to use DC motors, brushless motors, or servomotors (Table 1). An exception is a quadruped soft-amphibious robot with pneumatic actuation [88].

There is also a series of interesting Gecko-like robots capable of climbing [86], [87]. Among those, Stickybot is capable of climbing smooth vertical surfaces and replicates several features of the Gecko including a sprawling posture, a hierarchy of compliant structures, compliant feet with directional adhesion, and a mechanism for toe curling and peeling off feet [86]. 
Several interesting robotic studies focused specifically on the use of tails, for instance for improving climbing in the RiSE (Robot in Scansorial Environment) robot [93], [14], for inducing rapid turns in a small palm-sized hexapod [94], for stabilizing lizard-like bipedal running [95], for handling granular media and inclines [96], or for swimming [97], [98]. Another study, published in Nature, investigated the use of tails for stabilizing body attitude in the sagittal plane [99]. For this, the authors developed a lizard-sized robot with an active tail that used sensory feedback to stabilize pitch. They demonstrated that the state-dependent active tail movements allowed to reduce rotation compared to a body with a rigid tail, a passively compliant tail or no tail [99].

Finally, robots have also been designed to investigate more unusual modes of lizard locomotion such as water running robots replicating the basilisk lizard's ability to run on the surface of water [100]-[102] and swimming snake-like robot replicating the ability of the sandfish lizard to swim through sand [85].

Note that some quadruped robots without articulated spine like the Titan robot series [103], [89] can take a sprawling posture for increasing stability. Also there are quite a few amphibious legged robots capable of ground and water locomotion, such as for instance Rhex [104], AQUA [105], AmphiHex [106], RoboTerp [90], and Ariel (an amphibious robot to locate mines, produced by iRobot).

In my laboratory, we have developed a series of amphibious sprawling legged robots. The first one was Salamandra robotica I [65]. The robot was designed to test hypotheses concerning the organization of the spinal locomotor networks, and in particular, the mechanisms of gait transition from swimming to walking (see Sections 3 and 4). The robot was designed to be one of the simplest possible approximations of a salamander body capable of swimming and walking. The robot was driven by 10 DC motors: 6 motors for spine modules ( 3 in the trunk and 3 in the tail) for lateral undulation, and 4 motors for rotational limbs (Figure $3 \mathrm{~J}$ ). The rotational speed of the limbs was adjusted to have a fast swing movement and a slow stance in order to match the duty factor of salamanders (approximately 60\%). The movements of the robot were controlled by a CPG model made of coupled oscillators (see Section 4) programmed on a micro controller.

Salamandra robotica II (Figure 3K) was a new and improved version of Salamandra robotica I [45]. The novel features of the robot include two more actuated degrees of freedom in the spine, higher torques (12 DC motors in total), improved electronics, a new limb design that could passively fold against the body in water for lower drag, and a passive tail. These new features led to significantly faster swimming and walking compared to Salamandra robotica I. In particular, the robot could match the stride length in water and on ground of the salamander Pleurodeles waltl. The robot was also used to show that the tail can be used as a fifth limb in case of walking on slippery surfaces, similarly to what salamanders do [107].

The next robot was Pleurobot, a robot driven by 27 high-end servomotors (Figure $3 \mathrm{~L}$ ). The robot was designed to closely match three-dimensional X-ray videos of salamanders, Pleurodeles waltl, walking on ground, walking underwater and swimming. Tracking up to 64 points on the animal's skeleton we were able to record three-dimensional movements of bones in great detail. Using optimization on all the recorded postures for the three gaits, we deduced the number and 
position of active and passive joints needed for the robot to reproduce the animal movements in reasonable accuracy in three-dimensions. This led to a robot with more complex limbs than Salamandra robotica I and II. Structural elements were 3D printed (instead of molded as in the previous robots). The robot could closely replicate the salamander walking and swimming gaits (Figure 1). It was also used in a hybrid experiment where recording from left and right parts of the brainstem (the reticulospinal neurons) of a salamander could be used to steer the locomotion of the robot [108]. The most recent addition to the family of robots is OroBOT (Figure 3M), which will be described in Section 7.

\section{CONTROL OF MULTIMODAL LOCOMOTION}

The control of amphibious and sprawling robots presents both opportunities and challenges. As we have seen in the introduction, amphibious and sprawling locomotion presents several interesting characteristics. One opportunity is the large variety of different modes of locomotion that those robots could in principle perform similarly to those of their biological counter parts. Another benefit is the large support polygons for ground locomotion, which simplify balance control. But there are also challenges. First, the robot controller has to deal with many degrees of freedom as these robots can have up to 27 actuated motors, as in Pleurobot for instance. Second, such robots have no obvious reference frame. In a legged robot with rigid spine/body, the local coordinate system is typically fixed to, and aligned with, the body. That coordinate system can then be used to compute heading and foot placement commands. In a sprawling robot with articulated spine, all modules continuously change their orientation and there is no obvious choice of a particular module to serve as anchor for a reference frame. Third, sprawling robots often have multiple contacts with the ground, with not only leg contacts, but possibly also intermittent tail and trunk contacts. Since it is difficult to sense all these contacts and the underlying interaction forces, some model-based control approaches typically used in legged robots cannot be applied (note that, as mentioned above, these multiple contacts, and more generally the large support polygons, are also an advantage because they decrease the risk of falling over compared to mammalian-like quadruped robots). Fourth, sprawling robots have often limited ground clearance. This can generate problems in crossing irregular terrain and in stepping over obstacles. Finally, these robots need controllers than can actually perform multimodal locomotion with, for instance, transitions between swimming, crawling, and walking gaits (not to mention climbing and other possible gaits). A good locomotion controller should be able to generate these different gaits and to determine when it is best to switch between them.

So far, these challenges have only been partially overcome. Different control strategies have been tested including bio-inspired controllers [45], [65], finite-state machines, clock-based controllers [91], model predictive control [109], and controllers based on geometric mechanics [46].

Bioinspired locomotion controllers are often based on CPG models, for instance implemented as networks of coupled oscillators [45], [65], [110], or variations thereof [91]. These models are 
directly inspired by the salamander locomotor circuits, and are well suited for generating multiple gaits and switching between them. They are also well suited for distributed implementation, for instance, with oscillators running on different microcontrollers that communicate through a bus. For instance, Jeremie Knüsel programmed Salamandra robotica II in that way in his PhD thesis and demonstrated that different parts of the robot could keep moving even when the robot was split into two or more parts [111]. Recently, it was shown that sensory feedback from load and stretch sensors could contribute to synchronize oscillators of limb and axial CPGs [112]. Interestingly, in that work sensory feedback is the only means of synchronization (i.e. there are no direct couplings between oscillators), demonstrating that feedback might be as important as direct coupling in generating various locomotor patterns.

Another approach is to implement controllers based on inverse kinematics [28], [113], [114]. This can be done by separating the control of the spine undulation from that of the legs [113], or by having a full-body controller that solves inverse kinematics for both [114], in order to have a better control over turning. Reflexes such as leg extension reflex (when the leg loses contact with the ground during stance) or stumbling correction reflex (when the leg touches the ground during swing) can help these inverse-kinematics based controllers to cope with obstacles and irregularities of the terrain [94]. These controllers can also be extended with a model predictive control layer to monitor center of mass projections and improve balance control for different types of walking gaits [109].

Geometric mechanics can also provide an interesting formalism to characterize and plan gaits for sprawling robots. Zhong and colleagues have used such an approach to design different gaits for a salamander-like robot [46]. Similarly to [45], they found that the particular body-limb coordination exhibited by salamander during walking is close to the optimal one in terms of forward locomotion.

Table 1: Characteristics of different sprawling robots. DOF stands for degrees of freedom. DC motor stands for direct current motor. CPG stands for central pattern generator. MPC stands for model predictive control.

\begin{tabular}{|l|l|l|l|l|l|l|}
\hline Robot & $\begin{array}{l}\text { Number of } \\
\text { actuated } \\
\text { DOFs }\end{array}$ & $\begin{array}{l}\text { Type of } \\
\text { motors }\end{array}$ & $\begin{array}{l}\text { Type of } \\
\text { sensors }\end{array}$ & Control method & $\begin{array}{l}\text { Type of } \\
\text { gaits }\end{array}$ & Specific feature \\
\hline $\begin{array}{l}\text { Geo [91] } \\
\text { 4 per leg, } \\
3 \text { in trunk }\end{array}$ & $\begin{array}{l}\text { Servo- } \\
\text { motors }\end{array}$ & $\begin{array}{l}\text { Joint angle, } \\
\text { Load cells, } \\
\text { Accelero- } \\
\text { meters, } \\
\text { Gyroscopes }\end{array}$ & $\begin{array}{l}\text { CPG based on ring } \\
\text { rules }\end{array}$ & Walking & $\begin{array}{l}\text { Can be } \\
\text { reconfigured into } \\
\text { a mammalian-like } \\
\text { quadruped. }\end{array}$ \\
\hline $\begin{array}{l}\text { Robo- } \\
\text { Salamand } \\
\text { er [92] }\end{array}$ & $\begin{array}{l}10 \text { per leg, } \\
2 \text { in trunk }\end{array}$ & $\begin{array}{l}\text { Servo- } \\
\text { motors }\end{array}$ & Joint angle & Neural network & Walking & \\
\hline $\begin{array}{l}\text { Soft } \\
\text { amphibio } \\
\text { us robot } \\
\text { [88] }\end{array}$ & $\begin{array}{l}16 \text { per leg } \\
4 \text { in trunk }\end{array}$ & $\begin{array}{l}\text { Soft } \\
\text { McKibben } \\
\text { actuators }\end{array}$ & None & $\begin{array}{l}\text { Open-loop } \\
\text { pressure patterns }\end{array}$ & $\begin{array}{l}\text { Walking, } \\
\text { aquatic } \\
\text { stepping }\end{array}$ & $\begin{array}{l}\text { First soft } \\
\text { salamander-like } \\
\text { robot }\end{array}$ \\
\hline $\begin{array}{l}\text { Sand } \\
\text { swimming }\end{array}$ & $\begin{array}{l}\text { 6: in } \\
\text { trunk/tail }\end{array}$ & $\begin{array}{l}\text { Servo- } \\
\text { motors }\end{array}$ & Joint angle & $\begin{array}{l}\text { Open-loop } \\
\text { traveling waves }\end{array}$ & $\begin{array}{l}\text { Sand } \\
\text { swimming }\end{array}$ & $\begin{array}{l}\text { Robot without } \\
\text { legs }\end{array}$ \\
\hline
\end{tabular}


Preprint. The official article: http://dx.doi.org/10.1146/annurev-control-091919-095731

\begin{tabular}{|c|c|c|c|c|c|c|}
\hline $\begin{array}{l}\text { robot } \\
{[85]}\end{array}$ & & & & & & \\
\hline $\begin{array}{l}\text { Salamand } \\
\text { er-like } \\
\text { robot } \\
{[46]}\end{array}$ & $\begin{array}{l}\text { 9: } \\
2 \text { per leg, } \\
1 \text { in trunk }\end{array}$ & $\begin{array}{l}\text { Servo- } \\
\text { motors }\end{array}$ & Joint angle & $\begin{array}{l}\text { Open-loop } \\
\text { controller based } \\
\text { on geometric } \\
\text { mechanics }\end{array}$ & $\begin{array}{l}\text { Various } \\
\text { walking } \\
\text { gaits, } \\
\text { Side } \\
\text { stepping }\end{array}$ & $\begin{array}{l}\text { The robot was } \\
\text { also used to test } \\
\text { locomotion in } \\
\text { granular media }\end{array}$ \\
\hline $\begin{array}{l}\text { Alligator- } \\
\text { like robot } \\
{[83]}\end{array}$ & $\begin{array}{l}12: \\
2 \text { per leg, } \\
1 \text { in neck, } \\
1 \text { in trunk, } \\
2 \text { in tail }\end{array}$ & $\begin{array}{l}\text { Servo- } \\
\text { motors }\end{array}$ & Joint angle & $\begin{array}{l}\text { Open-loop } \\
\text { controller }\end{array}$ & Walking & $\begin{array}{l}\text { Open source } \\
\text { platform }\end{array}$ \\
\hline $\begin{array}{l}\text { AMOS- } \\
\text { WD02 } \\
{[84]}\end{array}$ & $\begin{array}{l}11: \\
2 \text { per leg, } \\
1 \text { in trunk, } \\
2 \text { in tail }\end{array}$ & $\begin{array}{l}\text { Servo- } \\
\text { motors }\end{array}$ & $\begin{array}{l}\text { Joint angle, } \\
\text { IR distance } \\
\text { sensors, } \\
\text { microphones, } \\
\text { wireless } \\
\text { camera }\end{array}$ & Neural network & Walking & $\begin{array}{l}\text { Capable of } \\
\text { obstacle } \\
\text { avoidance and of } \\
\text { escaping from } \\
\text { deadlock } \\
\text { situations }\end{array}$ \\
\hline $\begin{array}{l}\text { RoboTerp } \\
{[90]}\end{array}$ & $\begin{array}{l}8: \\
2 \text { per leg }\end{array}$ & $\begin{array}{l}\text { Waterpro } \\
\text { of servo- } \\
\text { motors }\end{array}$ & $\begin{array}{l}\text { Bump- } \\
\text { activated } \\
\text { switches, } \\
\text { water sensor }\end{array}$ & $\begin{array}{l}\text { Closed-loop } \\
\text { controller }\end{array}$ & $\begin{array}{l}\text { Swimming, } \\
\text { walking }\end{array}$ & $\begin{array}{l}\text { Equipped with } \\
\text { compliant flaps } \\
\text { for amphibious } \\
\text { locomotion }\end{array}$ \\
\hline $\begin{array}{l}\text { TITAN XIII } \\
\text { [89] }\end{array}$ & $\begin{array}{l}12: \\
3 \text { per leg }\end{array}$ & $\begin{array}{l}\text { Tendon- } \\
\text { driven } \\
\text { with } \\
\text { brushless } \\
\text { motors }\end{array}$ & Joint angle & $\begin{array}{l}\text { Inverse } \\
\text { kinematics } \\
\text { controller }\end{array}$ & Walking & $\begin{array}{l}\text { Nice study of cost } \\
\text { of transport. Very } \\
\text { fast walking gaits } \\
(1.38 \mathrm{~m} / \mathrm{s}) \text {. }\end{array}$ \\
\hline $\begin{array}{l}\text { StickyBot } \\
{[86]}\end{array}$ & $\begin{array}{l}12: \\
2 \text { per leg, } \\
1 \text { per feet for } \\
\text { peeling toes }\end{array}$ & $\begin{array}{l}\text { Servo- } \\
\text { motors }\end{array}$ & $\begin{array}{l}\text { Analog force } \\
\text { sensors }\end{array}$ & $\begin{array}{l}\text { Force-based } \\
\text { controller }\end{array}$ & Climbing & $\begin{array}{l}\text { Nice hierarchy of } \\
\text { compliant } \\
\text { structures for } \\
\text { directional } \\
\text { adhesion }\end{array}$ \\
\hline $\begin{array}{l}\text { Bio- } \\
\text { inspired } \\
\text { climbing } \\
\text { robot } \\
\text { [87] }\end{array}$ & $\begin{array}{l}\text { 8: } \\
2 \text { per leg }\end{array}$ & $\begin{array}{l}\text { Servo- } \\
\text { motors }\end{array}$ & Joint angle & $\begin{array}{l}\text { Open-loop } \\
\text { controller }\end{array}$ & Climbing & $\begin{array}{l}\text { Feet with flexible } \\
\text { pads and claws }\end{array}$ \\
\hline $\begin{array}{l}\text { Salamand } \\
\text { ra } \\
\text { robotica I } \\
{[65]}\end{array}$ & $\begin{array}{l}10: \\
1 \text { per leg, } \\
3 \text { in trunk, } \\
3 \text { in tail }\end{array}$ & $\begin{array}{l}\mathrm{DC} \\
\text { motors }\end{array}$ & Joint angle & CPG, open loop & $\begin{array}{l}\text { Swimming, } \\
\text { walking }\end{array}$ & $\begin{array}{l}\text { First amphibious } \\
\text { robot capable of } \\
\text { walking and } \\
\text { swimming }\end{array}$ \\
\hline $\begin{array}{l}\text { Salamand } \\
\text { ra } \\
\text { robotica II } \\
{[45]}\end{array}$ & $\begin{array}{l}12: \\
1 \text { per leg, } \\
4 \text { in trunk, } \\
4 \text { in tail }\end{array}$ & $\begin{array}{l}\mathrm{DC} \\
\text { motors }\end{array}$ & Joint angle & CPG, open loop & $\begin{array}{l}\text { Swimming, } \\
\text { walking }\end{array}$ & $\begin{array}{l}\text { Fast swimming } \\
\text { gaits }\end{array}$ \\
\hline $\begin{array}{l}\text { Pleurobot } \\
\text { [23] }\end{array}$ & $\begin{array}{l}27: \\
4 \text { per leg } \\
1 \text { in neck, } \\
5 \text { in trunk, } \\
5 \text { in tail }\end{array}$ & $\begin{array}{l}\text { Servo- } \\
\text { motors } \\
\text { (Dynamix } \\
\text { el) }\end{array}$ & $\begin{array}{l}\text { Joint angle, } \\
\text { IMU, } \\
\text { Force sensors }\end{array}$ & $\begin{array}{l}\text { CPG, } \\
\text { inverse } \\
\text { kinematics, } \\
\text { reflexes, } \\
\text { MPC. }\end{array}$ & $\begin{array}{l}\text { Swimming, } \\
\text { Aquatic } \\
\text { stepping, } \\
\text { walking }\end{array}$ & $\begin{array}{l}\text { 3D printed } \\
\text { structure, close } \\
\text { replica of } \\
\text { Pleurodeles waltl }\end{array}$ \\
\hline $\begin{array}{l}\text { OroBOT } \\
{[28]}\end{array}$ & $\begin{array}{l}28: \\
5 \text { per leg, } \\
2 \text { in neck, } \\
4 \text { in trunk }\end{array}$ & $\begin{array}{l}\text { Servo- } \\
\text { motors } \\
\text { (Dynamix } \\
\text { el) }\end{array}$ & Joint angle & $\begin{array}{l}\text { Inverse } \\
\text { kinematics }\end{array}$ & Walking & $\begin{array}{l}\text { 3D printed } \\
\text { structure, close } \\
\text { replica of the } \\
\text { Orobates fossil }\end{array}$ \\
\hline
\end{tabular}


Preprint. The official article: http://dx.doi.org/10.1146/annurev-control-091919-095731

\begin{tabular}{|l|l|l|l|l|l|l|}
\hline & 2 in tail & & & & & \\
\hline
\end{tabular}




\section{ROBOTIC PALEONTOLOGY}

Robotics can offer interesting tools for paleontology, for instance to investigate possible gaits systematically and provide a quantitative methodology to assess likelihoods of gaits of extinct animals [115]-[117], [96]. One example is a recent modeling and robotic study of Orobates [28]. The Orobates is an extinct 300-million old animal with a sprawling posture [118], [119] (Figure 4). It is likely a stem amniote, i.e. it represents the transition from anamniotes like salamanders (or other amphibian that have an amphibious lifestyle with aquatic larvae, e.g. the tadpoles of frogs) to amniotes like reptiles that are land-living vertebrates that lay eggs on dry land and have hatchlings that can live on land right away. It is also the oldest tetrapod for which both a complete fossil and fossilized footprints have been matched [120]. It therefore provides an exciting opportunity to investigate systematically which types of gaits could have been performed by that specific morphology to walk in those specific footprints.

To perform such a study, three models of the fossil were developed: a kinematic model with detailed bone geometry (Figure 4E), a robotic model OroBOT, that approximates the robot morphology with a series of rotational joints (Figure 4G), and a dynamic model, that constitutes a numerical simulation of the robotic model (Figure 4F). The purpose of the kinematic model was to assess anatomical plausibility of gaits, e.g. in terms of bone movements (e.g. avoiding bone collisions and joint dislocations). The purpose of OroBOT was to quantify the physics of locomotion (e.g. the mechanical power expenditure, and the ability to walk without excessive tilting, see below). In principle, only the dynamic simulation could have been sufficient for this, but having the real robot allowed us to verify the validity of the dynamic simulation, and to demonstrate that we could generate gaits in the real world.

The study also involved careful investigation of gaits of salamander, skink, iguana, and caiman. These animals were chosen to be different representatives of sprawling body plans and to provide a basis with which possible Orobates gaits could be compared. As discussed in Section 2, the gaits of these animals were carefully characterized within the sprawling gait space (SGS).

We tested hundreds of different gaits with our three types of models, in order to determine which ones Orobates most probably used or did not use. The gaits were generated with an inverse kinematics controller that could generate gaits matching idealized periodic footprints of the Orobates and that had sufficient open parameters such that a large volume of the SGS could be explored. In other words, we generated gaits that could walk in the footprints of Orobates at different values of body height, spine bending and long axis rotation.

In order to quantify the likelihood of gaits, we defined four metrics that measured: (i) the number of bone collisions (the fewer, the better), (ii) the mechanical power expenditure (the lower the better), (iii) the stability of the movements (the less roll and tilt, the better), (iv) how the ground reaction forces compare with the typical ground reaction forces of other sprawling animals, and (v) the accuracy in stepping in the fossilized footprints.

We concluded from this study that the Orobates could in principle have used many different types of gaits. But some gaits are more likely than others. The resulting gaits with highest scores appeared quite athletic, most closely resembling the movements of the caiman, indicating that 
Orobates most likely already held itself quite upright on its legs; unlike a salamander or skink, and thus exhibited more advanced locomotion than suspected.

The approach was validated with salamander and caiman data (see the extended data of [28]). In analogy to the workflow used for the fossil Orobates, we predicted the most likely gaits of a modern salamander and a caiman by matching morphology to foot prints. These predictions were met by actual locomotion characteristics of these species, for instance that salamanders move with a low posture and caimans with a high posture.

This study was therefore an example of how a robotics approach could contribute to paleontology. In particular, the robotic approach was useful to generate simulated and physical models, to generate gaits with inverse kinematics, and to create quantitative metrics for assessing the likelihood of gaits. Other metrics could be added, and some could be removed. In fact, users can make their own investigations on an interactive website ${ }^{2}$ and interactive simulation ${ }^{3}$ by modifying the weights assigned to different metrics, and observe how this changes the most likely gaits. The approach could be applied to other fossils. In case footprints are not available, different possible footprints could in principle be generated and investigated using the same metrics.

\footnotetext{
${ }^{2}$ https://biorob2.epfl.ch/pages/Orobates interactive

${ }^{3}$ https://cyberbotics2.cyberbotics.com/orobot/simulation.php
} 

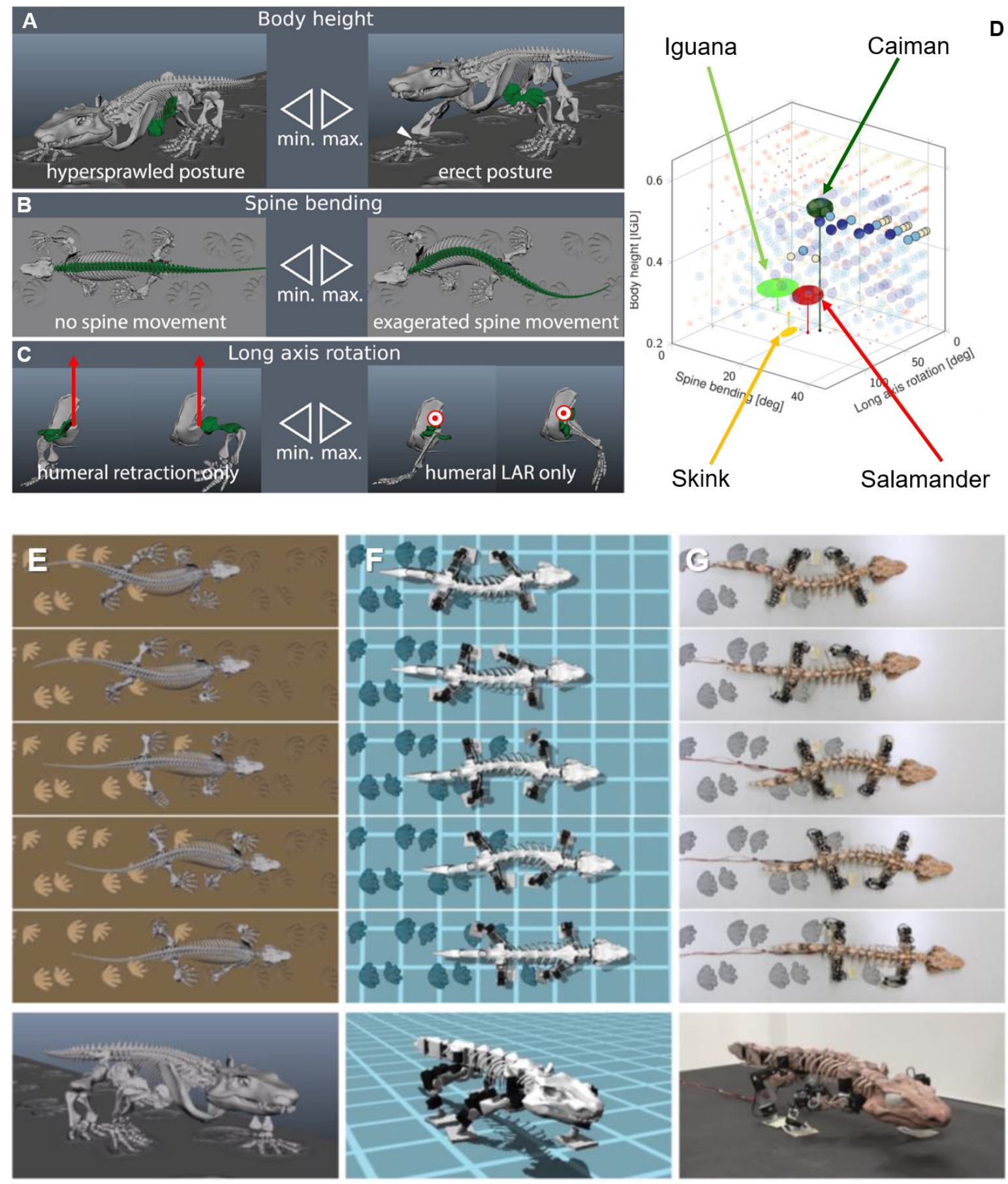

Figure 4: Robotic paleontology, study of possible gaits of the fossilized Orobates (adapted from [28], with reprint permission). A-C: Characterization of terrestrial sprawling gaits. The three quantities, body height (A), spine bending (B), and ratio between humeral long axis rotation versus retraction (C), define the sprawling gait space (SGS). The humeral retraction is a rotation around a vertical axis (in red in panel C). The humeral long axis rotation (LAR) is a rotation around an axis pointing out of the figure (red circle). D: Localization of salamander, skink, iguana, and caiman data in the SGS. Since the amount of humeral retraction is inversely proportional to the amount of LAR in all animals analyzed, only the LAR axis is shown to facilitate 3D viewing. Colored dots represent possible gaits of Orobates. The most likely ones (i.e. with a highest score for all metrics) are indicated in blue. E-G: snapshots of one of the most 
likely gaits of Orobates in the kinematic simulation (E), the dynamic simulation (F), and OroBOT (G). See also https://biorob2.epfl.ch/pages/Orobates interactive to access the data and the videos.

\section{DISCUSSION}

Understanding the principles of amphibious sprawling locomotion and designing robots that can perform this type of locomotion represents an interest research topic that is relevant for many fields. As reviewed in this article, it is worth taking a multidisciplinary approach to properly understand how the different underlying components interact, namely the central and peripheral nervous systems, the musculo-skeletal system, and the environments. It is also interesting to investigate how such locomotion existed in the past (e.g. as we saw in Orobates), and how it evolved from swimming animals and then led to more erect animals such as mammals. And obviously, robotics can immensely gain from all this knowledge, and in return provide tools to different scientific fields (e.g. neuroscience, biomechanics, and paleontology) to systematically and quantitatively test hypotheses.

There are still many open research questions both in terms of biology and of robotics. For instance, the role of different types of sensory feedback in gait generation and gait transition remains to be elucidated. The links between ecological niche, morphology and control could also be investigated further. For instance, there are many types of different salamander and lizard morphologies as well as different ecological niches in which they live. It would be interesting to systematically investigate which morphologies are well suited for which environment, and whether similar neural control principles could explain different gaits for these morphologies. Related to that, it would be worth making a comparative studies of amphibian vertebrates and invertebrates and investigate whether similar neural control principles are used by largely different species. Finally, it would be useful to generate a full lineage of neuromechanical models ranging from fish to amphibians to reptiles to investigate morphological (e.g. from fins to limbs) and neural adaptation during evolution.

In terms of robotics, many things remain to be done to improve the usefulness of amphibious sprawling robots. First, many robots developed so far remain fragile laboratory prototypes that have only partially been tested in complex outdoor environments. Robots need higher robustness (both mechanically and in terms of systems integration), better sensors, better actuators and better controllers in order to serve as useful devices for field missions. So far, robots based on simpler actuation systems (e.g. wheels, whegs, caterpillar tracks, and/or propellers) have had more success as field robots. But the potential of amphibious sprawling robots is very promising for various applications in inspection, search-and-rescue [121], and environmental monitoring. For instance, robots capable of salamander- and lizard-like multimodal locomotion could be very useful to inspect immersed or partially immersed pipes and caves, to monitor rivers, lakes and fish tanks, or to augment a rescue team that has to inspect collapsed and partially flooded structures. This will require not only good locomotion controllers but also higher-level sensing and controllers for localization, mapping, and autonomous or human-guided navigation. Finally, it would be interesting to design robots and locomotion controllers that can handle damage (e.g. a tail or limb loss) and adapt to different morphologies like their biological counterparts. Salamanders, for instance, have the impressive ability to regrow 
Preprint. The official article: http://dx.doi.org/10.1146/annurev-control-091919-095731

tails and even limbs, and to find ways to cope with these lesions. Designing robots and control architectures that can exhibit similar robustness would be an impressive achievement.

To conclude, the interdisciplinary research on amphibious sprawling locomotion is fascinating, full of interesting discoveries and with many interesting potential outcomes for the future understanding of biological organisms and design of robots alike.

\section{DISCLOSURE STATEMENT}

The author is not aware of any affiliations, memberships, funding, or financial holdings that might be perceived as affecting the objectivity of this review.

\section{ACKNOWLEDGEMENTS}

This work has been financially supported by the Human Frontier Science Program (project RGP0027/2017), the Swiss National Science Foundation (Project CR2312_140714), the Swiss National Center of Competence in Robotics, and the European Commission (EU FP7 Project Lampetra). I would like to thank Matthew Estrada, Daniel Goldman, Ardian Jusufi, Kamilo Melo, John Nyakatura, and Laura Paes for constructive comments on an earlier version of this article.

\section{LITERATURE CITED}

[1] R. Pfeifer, M. Lungarella, and F. lida, "Self-Organization, Embodiment, and Biologically Inspired Robotics," Science, vol. 318, no. 5853, pp. 1088-1093, Nov. 2007.

[2] F. lida and A. J. Ijspeert, "Biologically Inspired Robotics," in Springer Handbook of Robotics, B. Siciliano and O. Khatib, Eds. Cham: Springer International Publishing, 2016, pp. 20152034.

[3] A. J. Ijspeert, "Biorobotics: Using robots to emulate and investigate agile locomotion," Science, vol. 346, no. 6206, pp. 196-203, 2014.

[4] D. Floreano, A. J. ljspeert, and S. Schaal, "Robotics and neuroscience," Curr. Biol., vol. 24, no. 18, pp. R910-R920, 2014.

[5] J. Aguilar et al., "A review on locomotion robophysics: the study of movement at the intersection of robotics, soft matter and dynamical systems," Rep. Prog. Phys., vol. 79, no. 11, p. 110001, Sep. 2016.

[6] Y. O. Aydin, J. M. Rieser, C. M. Hubicki, W. Savoie, and D. I. Goldman, "6 - Physics approaches to natural locomotion: Every robot is an experiment," in Robotic Systems and Autonomous Platforms, S. M. Walsh and M. S. Strano, Eds. Woodhead Publishing, 2019, pp. 109-127.

[7] M. H. Raibert, Legged Robots that Balance. MIT Press, 1986.

[8] M. Raibert, M. Chepponis, and H. Brown, "Running on four legs as though they were one," IEEE J. Robot. Autom., vol. 2, no. 2, pp. 70-82, Jun. 1986. 
[9] M. Hutter et al., "ANYmal - toward legged robots for harsh environments," Adv. Robot., vol. 31, no. 17, pp. 918-931, Sep. 2017.

[10] P. M. Wensing, A. Wang, S. Seok, D. Otten, J. Lang, and S. Kim, "Proprioceptive Actuator Design in the MIT Cheetah: Impact Mitigation and High-Bandwidth Physical Interaction for Dynamic Legged Robots," IEEE Trans. Robot., vol. 33, no. 3, pp. 509-522, Jun. 2017.

[11] M. A. Sharbafi and A. Seyfarth, Bioinspired Legged Locomotion: Models, Concepts, Control and Applications. Butterworth-Heinemann, 2017.

[12] W. Wang et al., "Lateral undulation of the flexible spine of sprawling posture vertebrates," J. Comp. Physiol. A, vol. 204, no. 8, pp. 707-719, Aug. 2018.

[13] R. D. Maladen, Y. Ding, C. Li, and D. I. Goldman, "Undulatory Swimming in Sand: Subsurface Locomotion of the Sandfish Lizard," Science, vol. 325, no. 5938, pp. 314-318, Jul. 2009.

[14] A. Jusufi, D. I. Goldman, S. Revzen, and R. J. Full, "Active tails enhance arboreal acrobatics in geckos," Proc. Natl. Acad. Sci., vol. 105, no. 11, pp. 4215-4219, Mar. 2008.

[15] A. S. Romer, "The locomotor apparatus of certain primitive and mammal-like reptiles. Bulletin of the AMNH ; v. 46, article 10.," Locomotor apparatus of reptiles, 1922.

[16] O. R. Barclay, "The mechanics of amphibian locomotion," J. Exp. Biol., vol. 23, no. 2, pp. 177-203, 1946.

[17] R. D. Worthington and D. B. Wake, "Patterns of regional variation in the vertebral column of terrestrial salamanders," J. Morphol., vol. 137, no. 3, pp. 257-277, 1972.

[18] J. L. Edwards, "The evolution of terrestrial locomotion," in Major patterns in vertebrate evolution, M. K. Hecht, P. C. Goody, and H. B. M, Eds. Springer, 1977, pp. 553-577.

[19] A. H. Cohen, "Evolution of the vertebrate central pattern generator for locomotion," in Neural Control of Rhythmic Movements in Vertebrates, A. H. Cohen, S. Rossignol, and S. Grillner, Eds. Jon Wiley \& Sons, 1988.

[20] K.-Q. Gao and N. H. Shubin, "Late Jurassic salamanders from northern China," Nature, vol. 410, pp. 574-577, 2001.

[21] J. A. Clack, "An early tetrapod from 'Romer's Gap,'” Nature, vol. 418, no. 6893, pp. 72-76, Jul. 2002.

[22] F. Galbusera and T. Bassani, "The Spine: A Strong, Stable, and Flexible Structure with Biomimetics Potential," Biomimetics, vol. 4, no. 3, p. 60, Sep. 2019.

[23] K. Karakasiliotis et al., "From cineradiography to biorobots: An approach for designing robots to emulate and study animal locomotion," J. R. Soc. Interface, vol. 13, no. 119, 2016.

[24] S. M. Reilly and M. J. Delancey, "Sprawling locomotion in the lizard Sceloporus clarkii: the effects of speed on gait, hindlimb kinematics, and axial bending during walking," J. Zool., vol. 243, no. 2, pp. 417-433, 1997.

[25] R. Ritter, "Lateral Bending During Lizard Locomotion," J. Exp. Biol., vol. 173, no. 1, pp. 110, Dec. 1992.

[26] M. A. Ashley-Ross and B. F. Bechtel, "Kinematics of the transition between aquatic and terrestrial locomotion in the newt Taricha torosa," J. Exp. Biol., vol. 207, pp. 461-474, 2004.

[27] J. Gray, "Studies in the Mechanics of the Tetrapod Skeleton," J. Exp. Biol., vol. 20, no. 2, pp. 88-116, Jun. 1944.

[28] J. A. Nyakatura et al., "Reverse-engineering the locomotion of a stem amniote," Nature, vol. 565, no. 7739, p. 351, Jan. 2019.

[29] K. D'Août and P. Aerts, "Kinematics and efficiency of steady swimming in adult axolotls (Ambystoma mexicanum)," J. Exp. Biol., vol. 200, no. 13, pp. 1863-1871, Jul. 1997. 
[30] F. Seebacher, P. G. Elsworth, and C. E. Franklin, "Ontogenetic changes of swimming kinematics in a semi-aquatic reptile (Crocodylus porosus)," Aust. J. Zool., vol. 51, no. 1, pp. 15-24, 2003.

[31] K. M. Sheffield and R. W. Blob, "Loading mechanics of the femur in tiger salamanders (Ambystoma tigrinum) during terrestrial locomotion," J. Exp. Biol., vol. 214, no. 15, pp. 2603-2615, Aug. 2011.

[32] Gy. Székely, G. Czéh, and Gy. Vöeös, "The activity pattern of limb muscles in freely moving normal and deafferented newts," Exp. Brain Res., vol. 9, no. 1, pp. 53-62, Aug. 1969.

[33] L. M. Frolich and A. A. Biewener, "Kinematic and electromyographic analysis of the functional role of the body axis during terrestrial and aquatic locomotion in the salamander It Ambystoma Tigrinum," J. Exp. Biol., vol. 62, pp. 107-130, 1992.

[34] I. Delvolvé, T. Bem, and J.-M. Cabelguen, "Epaxial and limb muscle activity during swimming and terrestrial stepping in the adult newt, it Pleurodeles Waltl," J. Neurophysiol., vol. 78, pp. 638-650, 1997.

[35] M. A. Ashley-Ross and G. V. Lauder, "Motor patterns and kinematics during backward walking in the Pacific Giant Salamander: evidence for novel motor output," J. Neurophysiol., vol. 78, pp. 3047-3060, 1997.

[36] S. M. Deban and N. Schilling, "Activity of trunk muscles during aquatic and terrestrial locomotion in Ambystoma maculatum," J. Exp. Biol., vol. 212, no. 18, pp. 2949-2959, Sep. 2009.

[37] W. R. Moberly, "The metabolic responses of the common iguana, Iguana iguana, to walking and diving," Comp. Biochem. Physiol., vol. 27, no. 1, pp. 21-32, Oct. 1968.

[38] K. Autumn, R. B. Weinstein, and R. J. Full, "Low Cost of Locomotion Increases Performance at Low Temperature in a Nocturnal Lizard," Physiol. Zool., vol. 67, no. 1, pp. 238-262, Jan. 1994.

[39] K. Karakasiliotis, N. Schilling, J.-M. Cabelguen, and A. J. ljspeert, "Where are we in understanding salamander locomotion: biological and robotic perspectives on kinematics," Biol. Cybern., vol. 107, no. 5, pp. 529-544, Oct. 2013.

[40] K. Autumn, S. T. Hsieh, D. M. Dudek, J. Chen, C. Chitaphan, and R. J. Full, "Dynamics of geckos running vertically," J. Exp. Biol., vol. 209, no. 2, pp. 260-272, 2006.

[41] M. A. Ashley-Ross, R. Lundin, and K. L. Johnson, "Kinematics of level terrestrial and underwater walking in the California newt, Taricha torosa," J. Exp. Zool. Part Ecol. Genet. Physiol., vol. 311A, no. 4, pp. 240-257, Apr. 2009.

[42] G. B. Gillis, "Undulatory Locomotion in Elongate Aquatic Vertebrates: Anguilliform Swimming since Sir James Gray," Am. Zool., vol. 36, pp. 656-665, 1996.

[43] P. L. Swanson, "The Iguana Iguana iguana iguana (L)," Herpetologica, vol. 6, no. 7, pp. 187193, 1950.

[44] J. L. Ringma and S. W. Salisbury, "Aquatic Locomotor Kinematics of the Eastern Water Dragon (Intellagama lesueurii)," J. Herpetol., vol. 48, no. 2, pp. 240-248, Sep. 2013.

[45] A. Crespi, K. Karakasiliotis, A. Guignard, and A. J. ljspeert, "Salamandra Robotica II: An amphibious robot to study salamander-like swimming and walking gaits," IEEE Trans. Robot., vol. 29, no. 2, pp. 308-320, 2013.

[46] B. Zhong et al., "Coordination of back bending and leg movements for quadrupedal locomotion," in Robotics: Science and Systems, 2018.

[47] M. Hildebrand, "Symmetrical Gaits of Horses," Science, vol. 150, no. 3697, pp. 701-708, 1965. 
[48] R. C. Snyder, “Adaptations for Bipedal Locomotion of Lizards," Am. Zool., vol. 2, no. 2, pp. 191-203, 1962.

[49] van Leeuwen J., Aerts P., Aerts Peter, Damme Raoul Van, D’Août Kristiaan, and Hooydonck Bieke Van, "Bipedalism in lizards: whole-body modelling reveals a possible spandrel," Philos. Trans. R. Soc. Lond. B. Biol. Sci., vol. 358, no. 1437, pp. 1525-1533, Sep. 2003.

[50] V. Allen, J. Molnar, W. Parker, A. Pollard, G. Nolan, and J. R. Hutchinson, "Comparative architectural properties of limb muscles in Crocodylidae and Alligatoridae and their relevance to divergent use of asymmetrical gaits in extant Crocodylia," J. Anat., vol. 225, no. 6, pp. 569-582, 2014.

[51] G. R. Zug, "Crocodilian Galloping: An Unique Gait for Reptiles," Copeia, vol. 1974, no. 2, pp. 550-552, 1974.

[52] S. T. Hsieh and G. V. Lauder, "Running on water: Three-dimensional force generation by basilisk lizards," Proc. Natl. Acad. Sci., vol. 101, no. 48, pp. 16784-16788, Nov. 2004.

[53] J. A. Nirody et al., "Geckos Race Across the Water's Surface Using Multiple Mechanisms," Curr. Biol., vol. 28, no. 24, pp. 4046-4051.e2, Dec. 2018.

[54] G. M. Earhart and P. S. G. Stein, "Step, Swim, and Scratch Motor Patterns in the Turtle," J. Neurophysiol., vol. 84, no. 5, pp. 2181-2190, Nov. 2000.

[55] P. S. G. Stein, "Motor pattern deletions and modular organization of turtle spinal cord," Brain Res. Rev., vol. 57, no. 1, pp. 118-124, Jan. 2008.

[56] S. Grillner, "Biological Pattern Generation: The Cellular and Computational Logic of Networks in Motion," Neuron, vol. 52, no. 5, pp. 751-766, Dec. 2006.

[57] A. D. Kuo, "The Relative Roles of Feedforward and Feedback in the Control of Rhythmic Movements," Motor Control, vol. 6, no. 2, pp. 129-145, Apr. 2002.

[58] M. L. Shik, F. V. Severin, and G. N. Orlovsky, "Control of walking by means of electrical stimulation of the mid-brain," Biophysics, vol. 11, pp. 756-765, 1966.

[59] S. Mori, "Integration of posture and locomotion in acute decerebrate cats and in awake, freely moving cats," Prog. Neurobiol., vol. 28, no. 2, pp. 161-195, Jan. 1987.

[60] G. E. Loeb, "Learning from the spinal cord," J. Physiol., vol. 533, no. Pt 1, pp. 111-117, May 2001.

[61] D. Ryczko, V. Charrier, A. Ijspeert, and J.-M. Cabelguen, "Segmental oscillators in axial motor circuits of the salamander: Distribution and bursting mechanisms," J. Neurophysiol., vol. 104, no. 5, pp. 2677-2692, 2010.

[62] J. Cheng, R. B. Stein, K. Jovanovic, K. Yoshida, D. J. Bennett, and Y. Han, "Identification, Localization, and Modulation of Neural Networks for Walking in the Mudpuppy (Necturus Maculatus) Spinal Cord," J. Neurosci., vol. 18, no. 11, pp. 4295-4304, Jun. 1998.

[63] J. Cheng, K. Jovanovic, Y. Aoyagi, D. J. Bennett, Y. Han, and R. B. Stein, "Differential distribution of interneurons in the neural networks that control walking in the mudpuppy (Necturus Maculatus) spinal cord," Ex Brain Res, vol. 145, no. 2, pp. 190-198, 2002.

[64] A. J. ljspeert, "A connectionist central pattern generator for the aquatic and terrestrial gaits of a simulated salamander," Biol. Cybern., vol. 84, no. 5, pp. 331-348, 2001.

[65] A. J. Ijspeert, A. Crespi, D. Ryczko, and J.-M. Cabelguen, "From swimming to walking with a salamander robot driven by a spinal cord model," Science, vol. 315, no. 5817, pp. 14161420, 2007.

[66] D. Ryczko, R. Dubuc, and J.-M. Cabelguen, "Chapter 13 - Rhythmogenesis in axial locomotor networks: an interspecies comparison," in Progress in Brain Research, vol. 187, J.-P. Gossard, R. Dubuc, and A. Kolta, Eds. Elsevier, 2010, pp. 189-211. 
[67] D. Le Ray, L. Juvin, D. Ryczko, and R. Dubuc, "Chapter 4 - Supraspinal control of locomotion: The mesencephalic locomotor region," in Progress in Brain Research, vol. 188, J. P. Gossard, R. Dubuc, and A. Kolta, Eds. Elsevier, 2011, pp. 51-70.

[68] J. M. Cabelguen, C. Bourcier-Lucas, and R. Dubuc, "Bimodal locomotion elicited by electrical stimulation of the midbrain in the salamander Notophthalmus viridesecens," J. Neurosci., vol. 23, no. 6, pp. 2434-2439, 2003.

[69] J. D. Steeves, G. N. Sholomenko, and D. M. S. Webster, "Stimulation of the pontomedullary reticular formation initiates locomotion in decerebrate birds," Brain Res., vol. 401, no. 2, pp. 205-212, Jan. 1987.

[70] S. Chevallier, A. J. Ijspeert, D. Ryczko, F. Nagy, and J.-M. Cabelguen, "Organisation of the spinal central pattern generators for locomotion in the salamander: Biology and modelling," Brain Res. Rev., vol. 57, no. 1, pp. 147-161, Jan. 2008.

[71] D. Ryczko et al., "Flexibility of the axial central pattern generator network for locomotion in the salamander," J. Neurophysiol., vol. 113, no. 6, pp. 1921-1940, 2015.

[72] A. Bicanski et al., "Decoding the mechanisms of gait generation in salamanders by combining neurobiology, modeling and robotics," Biol. Cybern., vol. 107, no. 5, pp. 545564, 2013.

[73] A. J. ljspeert and J.-M. Cabelguen, "Control of Aquatic and Terrestrial Gaits in Salamander," Encycl. Comput. Neurosci., pp. 812-820, 2015.

[74] A. J. Ijspeert, A. Crespi, and J.-M. Cabelguen, "Simulation and robotics studies of salamander locomotion: Applying neurobiological principles to the control of locomotion in robots," Neuroinformatics, vol. 3, no. 3, pp. 171-195, 2005.

[75] J. Knuesel, K. Karakasiliotis, A. Crespi, D. Ryczko, J.-M. Cabelguen, and A. J. Ijspeert, "Gait transitions between swimming and walking in salamander: lessons from numerical modeling and robotics," Integr. Comp. Biol., vol. 53, p. E113, 2013.

[76] N. Harischandra et al., "Sensory Feedback Plays a Significant Role in Generating Walking Gait and in Gait Transition in Salamanders: A Simulation Study," Front. Neurorobotics, vol. 5, 2011.

[77] A. Bicanski, D. Ryczko, J.-M. Cabelguen, and A. J. Ijspeert, "From lamprey to salamander: an exploratory modeling study on the architecture of the spinal locomotor networks in the salamander," Biol. Cybern., vol. 107, no. 5, pp. 565-587, Oct. 2013.

[78] T. Bem, J.-M. Cabelguen, O. Ekeberg, and S. Grillner, "From swimming to walking: a single basic network for two different behaviors," Biol. Cybern., vol. 88, pp. 79-90, 2003.

[79] Ö. Ekeberg, "A combined neuronal and mechanical model of fish swimming," Biol. Cybern., vol. 69, pp. 363-374, 1993.

[80] J. Knuesel, J.-M. Cabelguen, and A. Ijspeert, Decoding the Mechanisms of Gait Generation and Gait Transition in the Salamander Using Robots and Mathematical Models. Oxford University Press, 2010.

[81] N. Harischandra, J.-M. Cabelguen, and Ö. Ekeberg, “A 3D Musculo-Mechanical Model of the Salamander for the Study of Different Gaits and Modes of Locomotion," Front. Neurorobotics, vol. 4, Dec. 2010.

[82] Q. Liu, H. Yang, J. Zhang, and J. Wang, "A new model of the spinal locomotor networks of a salamander and its properties," Biol. Cybern., vol. 112, no. 4, pp. 369-385, Aug. 2018.

[83] K. G. Karwa, S. Mondal, A. Kumar, and A. Thakur, "An open source low-cost alligatorinspired robotic research platform," in 2016 Sixth International Symposium on Embedded Computing and System Design (ISED), 2016, pp. 234-238. 
[84] P. Manoonpong, F. Pasemann, and H. Roth, "Modular reactive neurocontrol for biologically inspired walking machines," Int. J. Robot. Res., vol. 26, no. 3, pp. 301-331, 2007.

[85] R. D. Maladen, Y. Ding, P. B. Umbanhowar, A. Kamor, and D. I. Goldman, "Mechanical models of sandfish locomotion reveal principles of high performance subsurface sandswimming," J. R. Soc. Interface, vol. 8, no. 62, pp. 1332-1345, 2011.

[86] S. Kim, M. Spenko, S. Trujillo, B. Heyneman, D. Santos, and M. R. Cutkosky, "Smooth Vertical Surface Climbing With Directional Adhesion," IEEE Trans. Robot., vol. 24, no. 1, pp. 65-74, Feb. 2008.

[87] A. Ji, Z. Zhao, P. Manoonpong, W. Wang, G. Chen, and Z. Dai, “A Bio-inspired Climbing Robot with Flexible Pads and Claws," J. Bionic Eng., vol. 15, no. 2, pp. 368-378, Mar. 2018.

[88] A. A. M. Faudzi, M. R. M. Razif, G. Endo, H. Nabae, and K. Suzumori, "Soft-amphibious robot using thin and soft McKibben actuator," in 2017 IEEE International Conference on Advanced Intelligent Mechatronics (AIM), 2017, pp. 981-986.

[89] S. Kitano, S. Hirose, A. Horigome, and G. Endo, "TITAN-XIII: sprawling-type quadruped robot with ability of fast and energy-efficient walking," ROBOMECH J., vol. 3, no. 1, p. 8, Mar. 2016.

[90] A. R. Vogel, K. N. Kaipa, G. M. Krummel, H. A. Bruck, and S. K. Gupta, "Design of a compliance assisted quadrupedal amphibious robot," in 2014 IEEE International Conference on Robotics and Automation (ICRA), 2014, pp. 2378-2383.

[91] M. A. Lewis, "Self-organization of locomotory controllers in robots and animals," PhD Thesis, Faculty of the Graduate School, University of Southern California, 1996.

[92] R. Breithaupt, J. Dahnke, K. Zahedi, J. Hertzberg, and F. Pasemann, "Robo-Salamander - an approach for the benefit of both robotics and biology," in CLAWAR 2002, 2002.

[93] M. J. Spenko et al., "Biologically inspired climbing with a hexapedal robot," J. Field Robot., vol. 25, no. 4-5, pp. 223-242, 2008.

[94] N. J. Kohut, A. O. Pullin, D. W. Haldane, D. Zarrouk, and R. S. Fearing, "Precise dynamic turning of a $10 \mathrm{~cm}$ legged robot on a low friction surface using a tail," in 2013 IEEE International Conference on Robotics and Automation, 2013, pp. 3299-3306.

[95] J. Kim, H. Kim, Y. Kim, H. S. Kim, and J. Kim, "Design of Lizard-Inspired Robot with Lateral Body Motion," in 2018 IEEE/RSJ International Conference on Intelligent Robots and Systems (IROS), 2018, pp. 1-9.

[96] B. Mclnroe et al., "Tail use improves performance on soft substrates in models of early vertebrate land locomotors," Science, vol. 353, no. 6295, pp. 154-158, Jul. 2016.

[97] A. Jusufi, D. M. Vogt, R. J. Wood, and G. V. Lauder, "Undulatory Swimming Performance and Body Stiffness Modulation in a Soft Robotic Fish-Inspired Physical Model," Soft Robot., vol. 4, no. 3, pp. 202-210, May 2017.

[98] B. Wright, D. M. Vogt, R. J. Wood, and A. Jusufi, "Soft Sensors for Curvature Estimation under Water in a Soft Robotic Fish," in 2019 2nd IEEE International Conference on Soft Robotics (RoboSoft), 2019, pp. 367-371.

[99] T. Libby et al., "Tail-assisted pitch control in lizards, robots and dinosaurs," Nature, vol. 481, no. 7380, pp. 181-184, Jan. 2012.

[100] S. Floyd and M. Sitti, "Design and Development of the Lifting and Propulsion Mechanism for a Biologically Inspired Water Runner Robot," IEEE Trans. Robot., vol. 24, no. 3, pp. 698709, Jun. 2008. 
Preprint. The official article: http://dx.doi.org/10.1146/annurev-control-091919-095731

[101] H. S. Park, S. Floyd, and M. Sitti, "Roll and Pitch Motion Analysis of a Biologically Inspired Quadruped Water Runner Robot," Int. J. Robot. Res., vol. 29, no. 10, pp. 1281-1297, Sep. 2010.

[102] H. Kim, D. G. Lee, and T. Seo, "Rolling stability enhancement via balancing tail for a waterrunning robot," J. Bionic Eng., vol. 12, no. 3, pp. 395-405, Sep. 2015.

[103] S. Hirose et al., "Quadruped walking robots at Tokyo Institute of Technology," IEEE Robot. Autom. Mag., vol. 16, no. 2, pp. 104-114, Jun. 2009.

[104] U. Saranli, M. Buehler, and D. E. Koditschek, "RHex - A simple and highly mobile hexapod robot," Int. J. Robot. Res., vol. 20, no. 7, pp. 616-631, 2001.

[105] G. Dudek et al., "AQUA: An Amphibious Autonomous Robot," Computer, vol. 40, no. 1, pp. 46-53, Jan. 2007.

[106] S. Zhang, Y. Zhou, M. Xu, X. Liang, J. Liu, and J. Yang, “AmphiHex-I: Locomotory Performance in Amphibious Environments With Specially Designed Transformable Flipper Legs," IEEE-ASME Trans. Mechatron., vol. 21, no. 3, pp. 1720-1731, Jun. 2016.

[107] K. Karakasiliotis and A. J. Ijspeert, "Analysis of the terrestrial locomotion of a salamander robot," in 2009 IEEE/RSJ International Conference on Intelligent Robots and Systems, IROS 2009, 2009, pp. 5015-5020.

[108] D. Ryczko, R. Thandiackal, and A. J. ljspeert, "Interfacing a salamander brain with a salamander-like robot: Control of speed and direction with calcium signals from brainstem reticulospinal neurons," in Proceedings of the IEEE RAS and EMBS International Conference on Biomedical Robotics and Biomechatronics, 2016, vol. 2016-July, pp. 1140-1147.

[109] T. Horvat, K. Melo, and A. J. Ijspeert, "Model predictive control based framework for CoM control of a quadruped robot," in 2017 IEEE/RSJ International Conference on Intelligent Robots and Systems (IROS), 2017, pp. 3372-3378.

[110] Y. Cho, S. Manzoor, and Y. Choi, "Adaptation to environmental change using reinforcement learning for robotic salamander," Intell. Serv. Robot., vol. 12, no. 3, pp. 209-218, Jul. 2019.

[111] J. Knüsel, "Modeling a diversity of salamander motor behaviors with coupled abstract oscillators and a robot," PhD Thesis, EPFL, 2013.

[112] S. Suzuki, T. Kano, A. Ijspeert, and A. Ishiguro, "Decentralized control with cross-coupled sensory feedback between body and limbs in sprawling locomotion," Bioinspir. Biomim., 2019.

[113] T. Horvat, K. Karakasiliotis, K. Melo, L. Fleury, R. Thandiackal, and A. J. Ijspeert, "Inverse kinematics and reflex based controller for body-limb coordination of a salamander-like robot walking on uneven terrain," in 2015 IEEE/RSJ International Conference on Intelligent Robots and Systems (IROS), 2015, pp. 195-201.

[114] T. Horvat, K. Melo, and A. J. Ijspeert, "Spine Controller for a Sprawling Posture Robot," IEEE Robot. Autom. Lett., vol. 2, no. 2, pp. 1195-1202, Apr. 2017.

[115] V. Papantoniou, P. Avlakiotis, and R. McN. Alexander, "Control of a robot dinosaur," Philos. Trans. R. Soc. Lond. B. Biol. Sci., vol. 354, no. 1385, pp. 863-868, May 1999.

[116] J. H. Long, J. Schumacher, N. Livingston, and M. Kemp, "Four flippers or two? Tetrapodal swimming with an aquatic robot," Bioinspir. Biomim., vol. 1, pp. 20-29, 2006.

[117] W. I. Sellers and P. L. Manning, "Estimating dinosaur maximum running speeds using evolutionary robotics," Proc. R. Soc. B Biol. Sci., vol. 274, no. 1626, pp. 2711-2716, Nov. 2007. 
[118] D. S. Berman, A. C. Henrici, R. A. Kissel, S. S. Sumida, and T. Martens, "A new Diadectid (Diadectomorpha), Orobates pabsti, from the early permanian of central Germany," Bull. Carnegie Mus. Nat. Hist., vol. 2004, no. 35, pp. 1-36, Feb. 2004.

[119] J. A. Nyakatura et al., "A Three-Dimensional Skeletal Reconstruction of the Stem Amniote Orobates pabsti (Diadectidae): Analyses of Body Mass, Centre of Mass Position, and Joint Mobility," PLOS ONE, vol. 10, no. 9, p. e0137284, Sep. 2015.

[120] S. Voigt, D. S. Berman, and A. C. Henrici, "First well-established track-trackmaker association of paleozoic tetrapods based on Ichniotherium trackways and diadectid skeletons from the Lower Permian of Germany," J. Vertebr. Paleontol., vol. 27, no. 3, pp. 553-570, Sep. 2007.

[121] J. Delmerico et al., "The current state and future outlook of rescue robotics," J. Field Robot., vol. 36, no. 7, pp. 1171-1191, 2019. 